\title{
Why do some voluntary patients feel coerced into hospitalisation? A mixed-methods study
}

\author{
Christina Katsakou ${ }^{\mathrm{a}, *}$, Stamatina Marougka ${ }^{\mathrm{a}}$, Jonathan Garabette ${ }^{\mathrm{b}}$, Felicitas Rost ${ }^{\mathrm{c}}$, \\ Ksenija Yeeles ${ }^{\mathrm{d}}$, Stefan Priebe ${ }^{\mathrm{a}}$ \\ a Unit for Social \& Community Psychiatry, Barts and the London School of Medicine, Queen Mary University of London, London, United Kingdom \\ ${ }^{\mathrm{b}}$ Academic Division of Mental Health, St George's University of London, London, United Kingdom \\ c Psychotherapy Evaluation Research Unit, The Tavistock and Portman NHS Foundation Trust, London, United Kingdom \\ ${ }^{\mathrm{d}}$ Department of Psychiatry, University of Oxford, Warneford Hospital, Oxford, United Kingdom
}

\section{A R T I C L E I N F O}

\section{Article history:}

Received 9 April 2010

Received in revised form 22 September 2010 Accepted 6 January 2011

\section{Keywords:}

Coercion

Patient admission

Outcome Assessment (Health Care)

Inpatients

Qualitative research

\begin{abstract}
A B S T R A C T
This study aimed to investigate factors linked to perceived coercion at admission and during treatment among voluntary inpatients. Quantitative and qualitative methods were used. Two hundred seventy patients were screened for perceived coercion at admission. Those who felt coerced into admission rated their perceived coercion during treatment a month after admission. Patient characteristics and experiences were tested as predictors of coercion. In-depth interviews on experiences leading to perceived coercion were conducted with 36 participants and analysed thematically. Thirty-four percent of patients felt coerced into admission and half of those still felt coerced a month later. No patient characteristics were associated with perceived coercion. Those whose satisfaction with treatment increased more markedly between baseline and a month later were less likely to feel coerced a month after admission. In the qualitative interviews three themes leading to perceived coercion were identified: viewing the hospital as ineffective and other treatments as more appropriate, not participating in the admission and treatment and not feeling respected. Involving patients in the decision-making and treating them with respect may reduce perceived coercion.
\end{abstract}

(c) 2011 Elsevier Ireland Ltd. All rights reserved.

\section{Introduction}

It is commonly assumed that legally voluntary patients willingly participate in their care and do not feel under pressure to comply with hospital treatment. Research in this area, however, has revealed that between $10 \%$ and $50 \%$ of voluntary patients feel coerced into hospitalisation (Rogers, 1993; Monahan et al., 1995; Hiday et al., 1997). Admissions formally defined as voluntary are often the outcome of a complex process involving advice, persuasion, pressure and threats from patients' families or professionals (Kjellin et al., 2004). Hence, the legal status of admission is only a crude proxy for experienced coercion and many 'voluntary' patients feel excluded from treatment decisions and psychologically forced into hospitalisation (Sorgaard, 2007; Bindman et al., 2005).

'Procedural justice' (i.e. the perception of being respectfully involved in a fair decision-making process regarding admission) has been identified as predicting lower perceived coercion at admission among involuntary patients or mixed groups of involuntary and

\footnotetext{
* Corresponding author. Unit for Social and Community Psychiatry, Newham Centre for Mental Health, London E13 8SP, United Kingdom. Tel.: +44 2075406755; fax: +44 2075402976.

E-mail address: c.katsakou@qmul.ac.uk (C. Katsakou).
}

voluntary patients (Bennett et al., 1993; Lidz et al., 1995; Hiday et al., 1997; Lidz et al., 1998; McKenna et al., 2001). However, little is known on what patient characteristics or experiences elicit feelings of coercion among voluntary patients.

It is also unclear whether voluntary patients who initially feel coerced into admission continue to feel coerced during treatment and what factors are linked to such perceptions of coercion. It has been suggested that improving patients' satisfaction with their hospital treatment might lead to improved attitudes which might include lower perceived coercion, but this hypothesis has not been tested in previous research (Priebe and Gruyters, 1994; Priebe et al., 2009).

Reducing feelings of coercion is not only an ethical and humane issue, but might also lead to improved treatment outcomes. In effect, perceived coercion might lead to disengagement from services and negative therapeutic relationships (Lidz et al., 1998). Some studies also indicate that perceived coercion during hospitalisation leads to overall negative attitudes towards hospital treatment (Kaltiala-Heino et al., 1997; Gardner et al., 1999; Katsakou et al., 2010), poor clinical outcomes and reduced adherence to treatment after discharge (Luckstead and Coursey, 1995; Kaltiala-Heino et al., 1997).

The present study aimed a) to investigate whether specific sociodemographic and clinical characteristics are associated with perceptions of coercion at admission among legally voluntary patients, b) to examine whether voluntary patients who feel coerced into admission 
continue to feel coerced during hospital treatment, c) to indentify factors associated with feelings of coercion during treatment, and d) to explore what experiences - in the view of the patients - lead to feelings of coercion both at admission and during treatment.

\section{Methods}

We conducted an exploratory study, using both quantitative and qualitative methods. The methods were used concurrently during data collection. The quantitative and qualitative data were first analysed separately and later combined in the interpretation of the study findings. The study design, as described subsequently, was approved by the North East London Health Authority Research Ethics Committee.

\subsection{Quantitative study}

\subsubsection{Design, sample and procedure}

An observational prospective study was conducted in nine acute wards in two hospitals in East London. Consecutive legally voluntarily admitted patients were recruited between July and September 2003 and between November 2005 and July 2006. The recruitment of participants was conducted at two distinct time-periods for organisational reasons. Inclusion criteria were: age between 18 and 65 years, and residence in the catchment area of the participating hospitals. Exclusion criteria were a diagnosis of dementia, previous participation in the study and incapacity to give informed consent.

Eligible patients were identified through administrators or staff in the wards upon admission. Information on age, gender and diagnosis was collected for all eligible patients, to test the representativeness of the participating sample. Once identified, eligible patients were approached by researchers (independent from the patients care) and invited to take part in the study. Those who gave informed consent rated their perceived coercion at admission on the McArthur Perceived Coercion Scale (MPCS) within a week after admission (baseline). The scale measures five dimensions of perceived coercion (i.e. perceived control, choice, influence, freedom and idea). Scores ranged from 0 to 5 with higher scores indicating higher levels of coercion and the scale has been widely used and validated with inpatients (Gardner et al., 1993; Lidz et al., 1995, 1998; Kallert et al., 2005). Data on participants' ethnicity was also collected (census categories collapsed in two groups: white $=0$, non-white $=1$ ).

Those with a total score of at least 3 on the MPCS were considered coerced and were asked to complete an additional range of questionnaires at baseline and a followup interview one month after admission. All baseline interviews were conducted in the hospital. The follow-up interviews were completed either in the hospital or in the interviewees' homes.

\subsubsection{Additional measures for coerced patients at baseline and follow-up}

Those who felt coerced into admission (based on their MPCS scores) provided the following information at baseline: past hospitalisation (no past hospitalisation $=0$, at least one $=1$ ); employment (unemployed $=0$, employed $=1$ ); living situation (living alone $=0$, living with others i.e. with spouse and/ or children $=1$ ); satisfaction with treatment on the Client's Assessment of Treatment Scale (CAT). This scale comprises seven items and assesses patients' views on whether their treatment is right for them and whether they feel respected, as well as on specific treatment components (i.e. relationships with staff and medication). Each item is rated from 0 "not at all" to 10 "entirely satisfied" and the mean score was used for analyses. CAT has been used in large-scale studies of inpatient care (Priebe et al., 1995, 2006; Kallert et al., 2007). Researchers rated patients' functioning on the Global Assessment of Functioning (GAF), with scores ranging from 1 to 100 and higher scores indicating enhanced functioning, (American Psychiatric Association, 1994) and severity of symptoms on the 24-item Brief Psychiatric Rating Scale (BPRS) (Ventura et al., 1993). Each item is scored from 1 "not present" to 7 "extremely severe" and higher scores indicate more severe symptoms. The mean scores were used for analyses.

At follow-up interviews, participants were asked to rate their perceived coercion during hospital treatment. The MPCS only measures perceived coercion at admission and there are no validated instruments measuring perceived coercion during hospital treatment so the Coercion Ladder $(\mathrm{CL})$ was used for this purpose. $\mathrm{CL}$ is a visual analogue scale that has been used in conjunction with the MPCS and measures the degree of coercion, threats, or pressure patients experience during their hospital treatment (Hoyer et al., 2002; Kallert et al., 2005; Katsakou et al., 2010). Scores range from 1 to 10 , with higher scores indicating higher coercion. Satisfaction with treatment on CAT was also measured. Change on patients' satisfaction with their treatment was measured as the difference between one-month follow-up and baseline scores. Information on the total length of hospital stay, whether participants were still in hospital a month after admission and whether their legal status changed from voluntary to involuntary at any point throughout their stay (involuntary detention) was collected from medical records.

\subsubsection{Statistical analysis}

All eligible patients and study participants were compared at baseline on age, gender and diagnosis to assess the representativeness of the participating sample. Patients followed-up at one month were compared to those who considered themselves coerced and completed additional questionnaires at baseline, using all characteristics presented in Table 1 (i.e. age, gender, ethnicity, employment, living situation, past hospitalisation, diagnosis, perceived coercion at admission and during treatment, severity of symptoms, global functioning, treatment satisfaction, length of stay, and involuntary detention).

Scores on the MPCS were dichotomised, using 3 as a cut-off point to define perceived coercion (i.e. those with scores from 0 to 2 were considered 'not coerced' and those with scores from 3 to 5 'coerced'). Age, gender, ethnicity and diagnosis were tested as potential predictors of perceived coercion at admission using logistic regression.

Among those who felt coerced to admission, levels of perceived coercion during treatment (assessed a month after admission) were estimated using the CL. These scores were then dichotomised, with those scoring between 1 and 5 considered as 'not coerced' and those with ratings between 6 and 10 as 'coerced'. Baseline and treatmentprocess factors illustrated in Table 1 were tested as potential predictors of perceived coercion during treatment using logistic regression analysis. Since baseline and change scores of treatment satisfaction are interdependent, we tested only changes of satisfaction, which reflect treatment process, as a potential predictor variable.

The regression analysis for both outcomes (i.e. perceived coercion at admission and during treatment) was performed in two steps. First, univariate associations between each predictor variable and the outcome were calculated and if any variables were found significant at $P \leq 0.10$, they would be subsequently considered in a multivariable logistic regression model. Variables that became non-significant at $P=0.05$ would be excluded one by one until all the variables became significant. Stata version 9 was used for the analysis.

\subsection{Qualitative study}

\subsubsection{Sampling and data collection}

Three researchers conducted in-depth semi-structured interviews with patients, who were selected from the quantitative sample and gave additional informed consent to be interviewed qualitatively. The interviews were conducted within three months of the index admission, took place either in the hospital or in the interviewees' homes and lasted between 20 min and an hour.

The sampling was purposive. Patients who felt coerced into admission and a smaller group of patients who did not perceive any coercion were included. We included these two groups: a) to explore whether experiences reported by patients feeling coerced were specific to this group, i.e. were not shared by patients who did not feel coerced, and b) to identify experiences that do not lead to perceived coercion. The selection was based on patients' quantitative assessments on the MPCS. Similarly, participants with differing socio-demographic and clinical characteristics (i.e. age, gender, ethnicity, diagnosis, past hospitalisation) were selected to achieve an inclusive sample. Each participant was recruited on the basis of his/her potential similarities or discrepancy from patients already interviewed and sampling continued until saturation of the topics emerging from the interviews was reached (Miles and Huberman, 1994).

\subsubsection{Topic guide-interviews}

A topic guide for the interviews was finalised between four researchers. It covered patients' experiences of involuntary admission and treatment, including how the decision to admit them was reached, their involvement in the process, a description of the process itself, and their views on why they felt coerced or not.

\subsubsection{Data analysis}

All interviews were audio-recorded and transcribed verbatim. Participants were assigned to two different groups (coerced at admission versus not coerced) based on their scores on the MPCS. The transcripts were analysed thematically and the emerging themes in each group were counted (Boyatzis, 1998).

Three researchers read all interviews and developed a coding frame capturing the emerging themes, which was further discussed and refined in team meetings. To examine coding reliability, two researchers coded 10 out of the 36 (i.e. 28\%) transcripts together and agreed on the meaning and application of each code, as suggested by Miles and Huberman (1994). One researcher then coded all remaining transcripts, using the MAXqda software (Version 2) for qualitative data analysis. The coded segments and emerging themes were further discussed in team meetings.

The research team included researchers with a background in clinical and academic psychology (CK, SM, KY), academic psychology (FR), clinical and academic psychiatry (SP) and clinical psychiatry (JG). The group met regularly to discuss the study design, implementation, analysis and interpretation.

\section{Results}

\subsection{Quantitative study}

\subsubsection{Eligible patients and participants in baseline and follow-up interviews}

Out of the 446 eligible patients, 270 (61\%) agreed to participate in the study and completed the MPCS at baseline. Out of the 91 patients who felt coerced to admission (based on their MPCS scores), 83 (91\%) 
Table 1

Baseline and treatment characteristics for eligible patients and samples interviewed at baseline and at one-month follow-up.

\begin{tabular}{|c|c|c|c|c|}
\hline $\begin{array}{l}\text { Baseline and treatment-process } \\
\text { characteristics and outcomes }\end{array}$ & $\begin{array}{l}\text { Eligible sample } \\
(n=446)\end{array}$ & $\begin{array}{l}\text { Sample participating at } \\
\text { baseline }(n=270)\end{array}$ & $\begin{array}{l}\text { Coerced to admission with further } \\
\text { measures at baseline }(n=83)\end{array}$ & $\begin{array}{l}\text { Coerced to admission interviewed } \\
\text { at one-month follow-up }(n=58)\end{array}$ \\
\hline Age (years), $n$, mean (S.D.) & $445,36.42(11.29)$ & $270,36.35(11.64)$ & $83,35.84(11.56)$ & $58,35.08(11.68)$ \\
\hline Gender, $n(\%)$ Female Male & $187(42) 259(58)$ & $113(42) 157(58)$ & $41(49) 42(51)$ & $28(48) 30(52)$ \\
\hline Ethnicity, $n(\%)$ White Ethnic minority & & $121(47) 134(53)$ & 34 (41) 49 (59) & $23(40) 35(60)$ \\
\hline In employment, $n(\%)$ & & & $17(21)$ & $16(29)$ \\
\hline Living alone, $n(\%)$ & & & $44(56)$ & $31(56)$ \\
\hline Past hospitalisation, $n(\%)$ & & & $50(61)$ & $33(58)$ \\
\hline $\begin{array}{l}\text { Diagnosis, } n \text { (\%) Schizophrenia/psychosis } \\
\text { Affective disorder Other }\end{array}$ & 165 (37) 170 (38) $111(25)$ & $95(35) 111(41) 64(24)$ & $33(40) 27(32) 23(28)$ & $25(43) 19(33) 14(24)$ \\
\hline $\begin{array}{l}\text { Perceived coercion at admission }{ }^{\mathrm{a}}, n, \\
\text { mean (S.D.) }\end{array}$ & & $270,2.02(1.66)$ & $83,4.08(0.76)$ & $58,4.08(0.80)$ \\
\hline Severity of symptoms ${ }^{\mathrm{b}}, n$, mean (S.D.) & & & $83,2.11(0.44)$ & $58,2.12(0.45)$ \\
\hline Global functioning ${ }^{\mathrm{c}}, n$, mean (S.D.) & & & $83,30.88(12.13)$ & $58,31.07(12.61)$ \\
\hline $\begin{array}{l}\text { Satisfaction with treatment }{ }^{\mathrm{d}} \text { at baseline, } n \text {, } \\
\text { mean (S.D.) }\end{array}$ & & & $80,6.12(2.63)$ & $56,6.08(2.54)$ \\
\hline $\begin{array}{l}\text { Satisfaction with treatment }{ }^{\mathrm{d}} \text { at follow-up, } n \text {, } \\
\text { mean (S.D.) }\end{array}$ & & & & $57,6.37(2.41)$ \\
\hline $\begin{array}{l}\text { Improvement in satisfaction with treatment, } \\
n \text {, mean (S.D.) }\end{array}$ & & & & $56,0.25(2.35)$ \\
\hline Length of stay in days, $n$, mean (S.D.) & & & $81,30.15(33.63)$ & $57,34.14(36.62)$ \\
\hline Still in hospital at follow-up, $n$ (\%) & & & $32(40)$ & $25(44)$ \\
\hline $\begin{array}{l}\text { Involuntary detention during treatment, } n \\
(\%)\end{array}$ & & & $8(10)$ & $8(14)$ \\
\hline $\begin{array}{l}\text { Perceived coercion during treatment }{ }^{\mathrm{e}}, n, \\
\text { mean (S.D.) }\end{array}$ & & & & $56,5.41(3.48)$ \\
\hline $\begin{array}{l}\text { a MacArthur Perceived Coercion Scale, range } \\
\text { b Brief Psychiatric Rating Scale, range 0-7. } \\
\text { c Global Assessment of Functioning, range 1- } \\
\text { d Clients' Assessment of Treatment, range 1-- } \\
\text { e Coercion Ladder, range } 0-10 \text {. }\end{array}$ & $\begin{array}{l}0-5 . \\
100 . \\
7 .\end{array}$ & & & \\
\hline
\end{tabular}

completed additional questionnaires at baseline and 58 (70\%) were interviewed at one month follow-ups. From those interviewed at follow-ups, 25 (44\%) were still in hospital (for the index admission). The patient flow and reasons for non-participation in the study and missed follow-ups are shown in Fig. 1.

Table 1 shows the characteristics of all eligible patients and the samples participating in baseline and follow-up interviews. The distribution of the characteristics of eligible patients and the sample participating in the study and that between participants followed-up and those completing further questionnaires at baseline was similar.

\subsubsection{Perceived coercion at admission}

Out of the 270 patients who completed the MPCS, 91 (34\%) had a total score of 3 or above and were considered coerced. In univariate logistic regression models, only gender was a marginally significant predictor of perceived coercion, with female patients more likely to feel coerced (O.R. $=0.61,95 \% \mathrm{CI}=0.37$ to $1.02, P=0.061$ ). More specifically, 47 (40\%) females versus 44 (29\%) males felt coerced. Age, ethnicity and diagnosis were not significantly associated with perceived coercion at $P \leq 0.10$.

\subsubsection{Perceived coercion during treatment}

Twenty eight (50\%) patients who felt coerced into admission continued to feel coerced into treatment a month later based on their dichotomised CL scores. No significant associations were found with age, gender, ethnicity, employment status, living situation, past psychiatric hospitalisation, diagnosis, baseline symptoms, functioning, involuntary detention after the voluntary admission or whether the patient was still in hospital one month after the admission or not. The only factor statistically significantly associated with perceived coercion in the univariate models was improvement in treatment satisfaction between baseline and follow-up (O.R. $=0.59,95 \%$ $\mathrm{CI}=0.42$ to $0.84, P=0.003)$. Those whose treatment satisfaction increased more markedly between baseline and follow-up were less likely to feel coerced into treatment a month after admission.

\subsection{Qualitative study}

Three out of the 39 patients invited to take part in the study declined to do so. We conducted in-depth semi-structured interviews with 36 patients. Of these 23 felt coerced to admission based on their MPCS scores and 13 did not. As shown in Table 2, patients with various socio-demographic and clinical characteristics were represented in both the coerced and the non-coerced groups.

Experiences leading to patients feeling coerced are presented first, followed by experiences that did not lead to perceived coercion, and lastly by experiences that were shared by patients who did and those who did not feel coerced. The prevalence of these experiences in each group is presented in Table 2 and more quotes illustrating patients' views are shown in Box 1.

\subsubsection{Experiences leading to perceived coercion}

Patients who felt coerced described three themes leading to such feelings, i.e. perceiving the hospital treatment as not effective and alternative treatments as more appropriate, not participating sufficiently in the admission and treatment process and lastly not feeling respected and cared for by professionals.

3.2.1.1. Hospital treatment not effective/need for alternative treatment. The majority of patients who felt coerced (91\%) believed that they had mental health problems before admission and needed some help. However, they either viewed the hospital treatment as not effective, or believed that alternative treatments would be more beneficial. They thought that hospital care was mostly not helpful or harmful because of being confined and kept away from their families, having no privacy, and feeling scared by other patients. Overall, they perceived the hospital as a place where they were contained and 


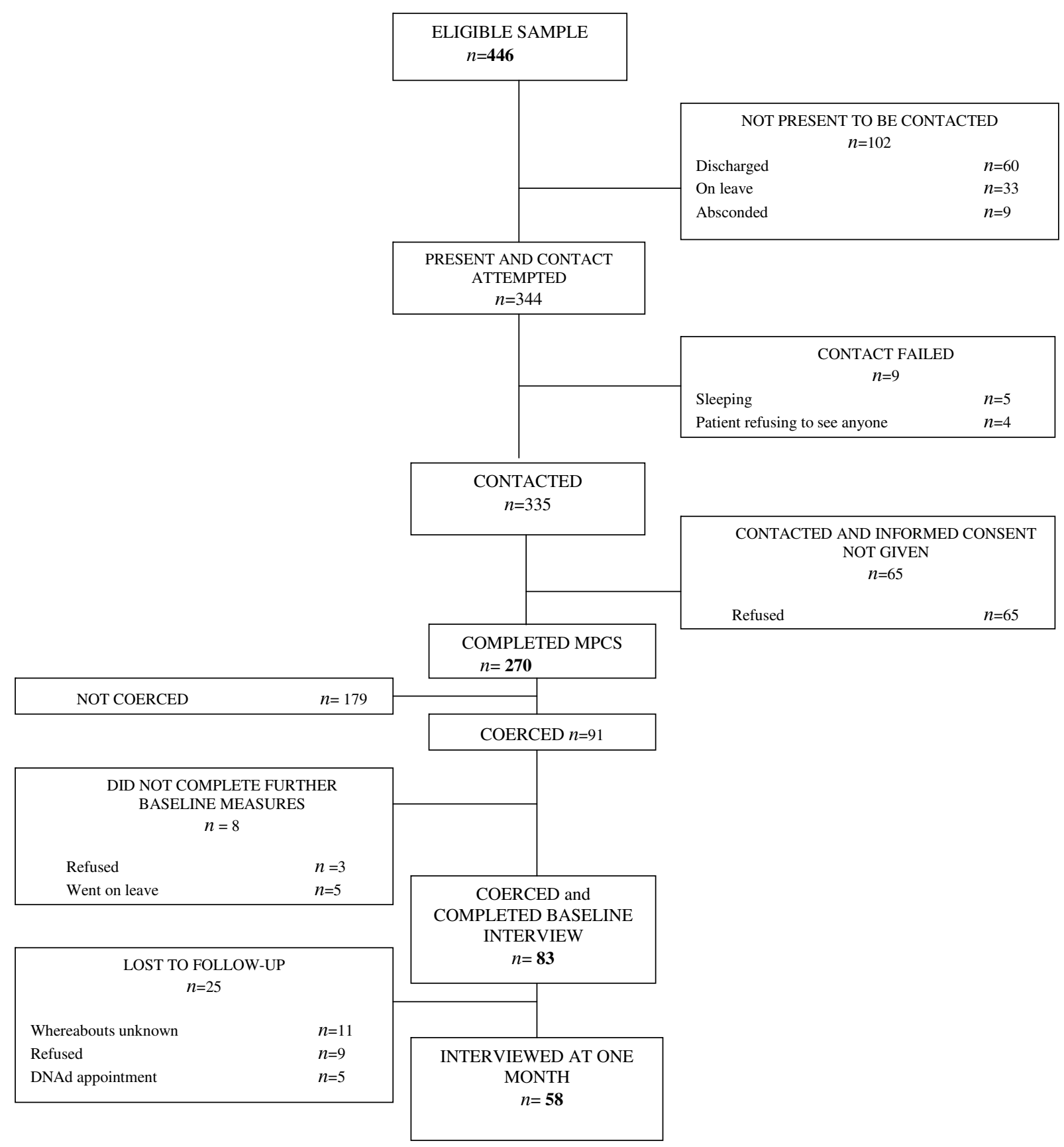

Fig. 1. Recruitment and follow-up flowchart.

given medication, not as a therapeutic environment. "I needed some sort of treatment, but I don't think to be locked up for 5 weeks is some sort of treatment" (participant 3).

Although they acknowledged the benefits of medication, they believed that more holistic and less restrictive treatments, such as day hospital, crisis houses or community treatment (including psychological therapies, or specialist services), would have been more appropriate. "The hospital is not good for me, it makes me more stressed. I like to be in me own flat and go to the day hospital everyday... that's where you get more respect, cause here [in hospital] they think you are an animal. I'd be so happy if I went to the day hospital" (participant 21).

Only two interviewees expressed different views on this theme and felt that they did not have any mental health problems or were at risk and so did not need treatment.
3.2.1.2. Not participating sufficiently in the admission and treatment process. Ninety-one percent of coerced patients believed that they did not have control over their admission and treatment. They felt they did not have the opportunity to choose between different options, they were not sufficiently involved in treatment decisions, and they were not given adequate information. They often felt threatened and that if they did not go to hospital "voluntarily" they would be admitted under a section of the Mental Health Act. "I didn't really decide, they decided for me... I thought that if I didn't say yes then I would be sectioned, so really I did feel coerced... it certainly didn't feel like I had a choice, so I got angry" (participant 15).

Even when information or some options were presented to them, they often felt that they did not have enough time to reflect and felt overwhelmed, bewildered and pushed into accepting admission. "I was scared, feeling like I don't want to go and half of me wanted to go, 
Table 2

Baseline characteristics and themes for participants in the in-depth interviews.

\begin{tabular}{|c|c|c|}
\hline Characteristics and themes & Coerced $(n=23)$ & Non-coerced $(n=13)$ \\
\hline \multicolumn{3}{|l|}{ Gender, $n(\%)$} \\
\hline Female & $11(48)$ & $7(54)$ \\
\hline Male & $12(52)$ & $6(46)$ \\
\hline Age (years), $n$, mean (S.D.) & $23,34.65(12.53)$ & $13,32.58(11.57)$ \\
\hline \multicolumn{3}{|l|}{ Ethnicity, $n(\%)$} \\
\hline White & $12(52)$ & $8(61)$ \\
\hline Ethnic minority & $11(48)$ & $5(39)$ \\
\hline Past hospitalisation, $n(\%)$ & $12(52)$ & $4(31)$ \\
\hline \multicolumn{3}{|l|}{ Diagnosis, $n$ (\%) Schizophrenia/ } \\
\hline psychosis & $5(22)$ & $2(15)$ \\
\hline Affective disorder & $10(43)$ & $7(54)$ \\
\hline Other & $8(35)$ & $4(31)$ \\
\hline Need for treatment/safety, $n(\%)$ & $15(65)$ & $13(100)$ \\
\hline Participating in the process, $n(\%)$ & $11(48)$ & $13(100)$ \\
\hline Feeling respected/cared for, $n(\%)$ & $12(52)$ & $11(85)$ \\
\hline $\begin{array}{l}\text { Hospital not effective/need for } \\
\text { alternative treatment, } n(\%)\end{array}$ & $21(91)$ & $3(23)$ \\
\hline $\begin{array}{l}\text { Not participating sufficiently in the } \\
\text { admission and treatment process, } n(\%)\end{array}$ & $21(91)$ & $5(38)$ \\
\hline Not feeling respected/cared for, $n(\%)$ & $13(57)$ & $2(15)$ \\
\hline
\end{tabular}

but everything happened so quickly that day, that I didn't have time to say anything... I just thought that I got pushed into doing it, it wasn't like I was asked for my consent, that was the whole problem ... In a way I wanted to face up to my problems... but I felt really intimidated, pressured into going" (participant 2).

Once in hospital, they felt that they had to comply with a routine that they were not introduced to. Decisions about their care were presented to them as fait accomplit without being clearly explained or negotiated. "Having your liberties taken away is not a pleasant thing, your choices. I had to eat at set times, I had to eat set foods... I did ask them if I could have my sleeping pill earlier because my general routine is going to bed early, but that wasn't possible so I had no choice over that either" (participant 32).

3.2.1.3. Not feeling respected/cared for. Over half (57\%) of patients felt that the staff involved in their admission and treatment did not care about them and were often rude and abrupt. "There's a whole team there and they don't listen to you; they TELL you... it just made me feel like I wasn't human and nobody actually took my point of view into consideration" (participant 32).

They also thought that professionals often used technical language that they could not understand. This perceived lack of respect made them feel devalued and coerced. "They are too professional and everything they've told me I don't understand, 'cause there's too many long words in there, and I feel embarrassed and shy, I feel demolished, I feel like an idiot asking them" (participant 28).

\subsubsection{Experiences not leading to perceived coercion}

Patients who did not feel coerced reported opposite experiences in all three themes described by coerced patients. More specifically, they believed that they needed hospital treatment, that they were included in the admission and treatment process, and that they felt respected and cared for. These experiences were associated with not feeling coerced.

3.2.2.1. Need for hospital treatment and safety. All patients who did not feel coerced believed that they had mental health problems that they could not control on their own and/or that they were at risk of harming themselves before admission. "The panic attacks usually last half an hour and I can control them... This one just went on, and on, and on. I tried to control it for about four hours, and then I said to my husband I have to get to hospital. Just to get away from the terror, I would have harmed myself I'm sure. I was trying to make myself unconscious by bashing my head on the floor" (participant 2).

They perceived that hospitalisation offered them the intensive treatment they needed and helped them recover in a place of safety. "I was feeling that people were following me, watching my every move. To me, the only safe place I felt was the psychiatric hospital" (participant 1 ).

3.2.2.2. Participating in the admission and treatment process. All patients who did not feel coerced believed that they either asked to be admitted themselves or were actively involved in their admission and treatment process. They thought that they were given information about the reasons for their admission, offered alternatives to hospital treatment, as well as time to consider their options and decide what the best course of action is. While in hospital, they believed that their problems and treatment was clearly explained to them and their preferences were taken into account.

"The mental health team said they'd visit me at home sometimes, but I thought it was better to come to hospital. The psychiatrist said that they couldn't do a lot for me unless I went to hospital. They were willing to do home visits ... but I thought it wasn't enough support" (participant 14).

3.2.2.3. Feeling respected/ cared for. The majority of patients who did not feel coerced (85\%) appreciated the staff's involvement in their admission and treatment. They believed that some professionals were caring and genuinely interested in them, supportive, empathetic and respectful. This made them feel like valued human beings and helped them acknowledge the benefits of their treatment.

"When you go through a dreadful breakdown, all you really crave for is somewhere safe and someone to understand and to just accept you, and, to actually treat me with dignity and just treat me as if I was my normal... and here I've been treated very, very nicely" (participant 1).

\subsubsection{Shared experiences among coerced and non-coerced patients}

Although some patients felt coerced into admission and treatment and others did not, each group reported both positive and negative experiences during the admission process and in the hospital 
Box 1

Quotes illustrating experiences leading to perceived coercion or not.

Patients perceiving coercion
Hospital treatment not effective/need for alternative treatment
"I don't see it like a treatment; I see it like just being locked away. I was under medication
yeah, but there was not a definitive programme that was working with helping me deal
with my mind" (participant 12).
"I wanted to go to an eating disorder clinic, it would be more beneficial because I would be
around people who have the same problems as me, and there will be a psychotherapists
there, who understand, who have been dealing with people like that for years"
(participant 9).

Patients not perceiving coercion

Need for treatment and safety

"I saw a baby girl, she jumped into my jacket pocket and I couldn't get her out, and I said look can you please help me get this baby out of my jacket pocket! She gonna die! $\mathrm{He}$ [the psychiatrist] obviously knew that there was nothing there but I didn't. It was so vivid, it was so real to me, and they admitted me. I really, really wanted to get admitted, because this has lasted for a while now and it's been getting worse, and I kept taking more and more tablets every 3 to 4 hours hoping that would fix it, but it didn't, and I was drinking as well, thinking that that might help, but it didn't" (participant 6).

"I didn't want to commit suicide anymore, I thought that I didn't need to be in hospital. I needed maybe to be seeing the psychologist more times than I was seeing him, maybe seeing the psychiatrist outside of the hospital to change my medication or increase it, but just not coming into the hospital... I don't know why they put me there to begin with. I didn't see a psychiatrist or anything, just once on the ward round" (participant 15).

"I thought that Crisis House would have been better for me cause it's kind of frightening sometimes to be here and watching other patients, but I suppose I'm here, and I do feel better so it couldn't have all been bad" (participant 27).

"I had gone into the ward feeling bad and it just made me feel worse I guess. I mean perhaps it was the right place for me but it didn't seem like anything was being done at the time. It seemed odd being in hospital and not seeing any sort of treatment at all" (participant 30).

Not participating sufficiently in the admission and treatment

"It was like we were backed into a corner, my mum almost had to convince him to let me come in on the Saturday because otherwise he wanted me to come in then and there, that day, that night, so I hadn't no choice and obviously I didn't want to be sectioned you know, because that's going to be stuck with me for ever. So there was no choices like, we had no discussion, I was adamant that I didn't want to come in, but I didn't want to be sectioned, so I had no choice about it whatsoever" (participant 9).

"I think [if I was not admitted] I would have gone home and I would have self-harmed. I would have probably got a knife and gone for me wrists, and said please somebody notice that I need help...I felt here [in hospital] I'd get more intense treatment and therapy than home treatment team, sort of people popping in and out" (participant 13).

“It's right coming to hospital. I really needed that help, I really do need help to get myself strong and stand on my own two feet, stop phoning my mum like I do for reassurance. I needed time away from her, time to myself, needed just a lot of rest. I'm not independent at the moment, I feel like a, 5 year old kid " (participant 8).

"I'm here now getting better, resting my head, I need to get well now" (participant 20).

"They didn't really tell me what was going on, they just sort of left me there... then they said to me that I couldn't just go... they said that they would take me in a cab, to this hospital to see my doctor for 20 minutes and then go straight home in a cab again. So I didn't really know where I was, in terms of a hospital ... When I came here they said your bed's ready, and gave me pyjamas! I was like what, you know, I'm only here for 20 minutes, it was like all a big mistake!" (participant 22).

"I was taken into the ward, I wasn't given any sort of introduction or induction; just a nurse pointed out that's where you are sleeping. Then I had a weekend when nothing really happens in there and I was just feeling lost and lonely, I wasn't introduced to other patients or any of the nurses" (participant 31).

"I mean my big problem is my lack of self esteem that's where all my problems come from, and to be locked in hospital like that just exacerbates that problem, fuels all the insecurities I have, um, it seems like I had no power or control over what happens to myself, um which is precisely the sort of reason why I took an overdose in the first place" (participant 30).

Not feeling respected/cared for

“They don't talk to you ...it's bad. They don't speak to you and see that you are okay, they don't, it's bad" (participant 21).

"Being on the ward, no one wanted to help me" (participant 7).

"I felt that the duty doctor could have been more polite, 'cause that sort of made me think that I was a bad person, the way she talked" (participant 15).

"It's important for them to understand how scared we are and how much we're going through; to recognise that it's a big deal if someone's in the hospital, it's not just a little thing... and they don't" (participant 34).

Participating in the admission and treatment process

"They suggested doing something at home, where somebody comes in everyday, and talks to you, and sees how you are getting on. I didn't like the sound of that cause I suffer panic and anxiety attacks and with my depression some days I don't want to get out of bed, I don't want to see anybody, I don't want to speak to anybody. And plus I don't like people in where I live. I felt here I'd get more intense treatment and therapy than sort of people popping in and out" (participant 13).

"The duty psychiatrist spent like about an hour with me, asking various questions and then he started to advise me on what he thought was the best course of action for me. He sort of told me what he thought was the initial kick off of the problem, but as we got chatting and talking more came out, and he seemed to think that there was something more deep-seated in the problem. So he then advised me basically to come in here, until they can work out some sort of programme for me... and I followed his advice. It was entirely my choice" (participant 29).

"I came into the A\&E, and the reason why I came in was because I couldn't eat, I couldn't breathe, couldn't sleep, wandering around the room all night long and I said to my mum, I've got to go and get it checked out, so I came" (participant 8).

“They do talk to me and explain why I'm getting these things happening to me. I'm grateful, they've diagnosed me and told me what tablets they give me" (participant 4).

Feeling respected/cared for

"They were really good, really kind...the kindness, the understanding and thoughtfulness of people here... and there was no judgment, it wasn't like I'm mad or crazy..." (participant 26).

"That person [psychiatrist] was perfectly polite and helpful, it's not like the old days when you get stuck in a straight jacket and thrown in the cells. I was perfectly happy, nobody's been threatening at all, everybody's been really helpful" (participant 23).

"I think that I've been taken care of quite well, they've been supportive, they've talked to me, they're helping me as much as they can... I just wanted to get better, and I thought it's warm here, and they looked after me, and I felt safe" (participant 8). "They work towards my needs which was quite good... they were very flexible and understanding" (participant 25).
(Table 2). More specifically, a significant proportion of those who felt coerced believed that they did gain some benefits from their treatment (65\%), that they were involved in some aspects of their care $(48 \%)$ and that some members of staff were supportive and caring (52\%). Similarly, some of those who did not perceive any coercion felt that some aspects of their treatment were not beneficial (23\%); that they were not always included in treatment decisions (38\%) and that some staff members were disrespectful or not caring (15\%). Nevertheless, the coerced group reported more negative experiences in total, whereas the non-coerced patients saw overall more positive aspects in their admission and treatment.

\section{Discussion}

\subsection{Main findings}

Approximately one third of legally voluntary patients felt coerced into admission and half of those continued to feel coerced into treatment a month later. No clinical or socio-demographic characteristics were significantly associated with perceived coercion. Patients who became more satisfied with treatment over time were less likely to feel coerced a month after admission. Viewing the hospital care as ineffective and alternative treatments as more appropriate, not 
participating in the admission and treatment process, and not feeling respected and cared for led to feelings of coercion. The opposite experiences and views, i.e. perceiving a need for hospital treatment, being involved in the admission and treatment process and feeling respected led to patients not feeling coerced.

\subsection{Strengths and limitations}

To our knowledge, this is the first study that assessed levels of, and factors linked to, perceived coercion both at admission and during treatment among voluntary patients. The combination of quantitative and qualitative methods provides a more comprehensive picture of characteristics and experiences leading to perceived coercion. A larger number of voluntary patients were assessed for perceived coercion at admission in comparison to previous studies (Lidz et al., 1995, 1998; McKenna et al., 2001). The number of patients participating in the qualitative interviews (36) also compares favourably with other qualitative studies with inpatients (Katsakou et al., 2007; Gilburt et al., 2008), and saturation of themes was achieved. Three researchers worked together on developing the coding frame and two researchers assessed reliability in coding, which reduces the risk of individual bias in the analysis and increases confidence in the results.

The study also has several limitations. Although socio-demographic and clinical patient characteristics were tested as potential predictors of perceived coercion at admission, admission-process characteristics were not considered. The sample size for estimating and predicting levels of coercion during hospital treatment was small (58 patients), with a limited statistical power to detect significant associations, so that negative findings should be interpreted cautiously. Lastly, this study only explored patients' perspectives, and the views of clinicians were not assessed.

\subsection{Findings in the context of previous evidence}

The relatively high proportion of voluntary patients feeling coerced into admission is consistent with findings from previous smaller investigations (Monahan et al., 1995; Hiday et al., 1997; Kaltiala-Heino et al., 1997; Bindman et al., 2005). To some extent, this might reflect clinicians' efforts to avoid the more coercive alternative of legally involuntary hospitalisation and their willingness to exert pressure on patients to accept admission when they believe that this is in their best interest (Seale et al., 2006; Katsakou and Priebe, 2006).

This study adds to previous evidence by demonstrating that half of those patients initially feeling coerced into admission continue to feel coerced into treatment a month later. Patients' initial negative attitudes towards their hospital treatment have often been interpreted as a manifestation of acute mental illness and lack of insight into their problems during a crisis situation (Beck and Golowka, 1988). Findings from this study, however, suggest that even a month later, when the acute phase of the illness is usually overcome, a significant proportion of patients continue to feel coerced. Thus, it becomes crucial to understand why some voluntary patients feel coerced, especially since perceived coercion might have a negative impact on treatment outcomes and overall engagement with services (Luckstead and Coursey, 1995; Kaltiala-Heino et al., 1997; Katsakou et al., 2010; Priebe et al., 2010; Bennewith et al., 2010).

In line with previous evidence, our findings highlight the importance of being included in treatment decisions and feeling respected and cared for in shaping patients' perceptions of coercion (Lidz et al., 1995; Hiday et al., 1997; Lidz et al., 1998; McKenna et al., 2001; Gilburt et al., 2008; Katsakou et al., 2010). Furthermore, the quantitative and qualitative findings from our study suggest that patients' appraisal of and satisfaction with their treatment are significantly linked to perceived coercion. Patients who regard their treatment as appropriate and effective are less likely to feel coerced. Even those who initially feel coerced into admission perceive less coercion a month later, if their satisfaction with their hospital treatment increases.

The positive impact of patients' initial assessment of their treatment on outcomes has been shown in various forms of psychiatric treatment, such as pharmacotherapy, psychotherapy, day hospital, and involuntary inpatient treatment (Van Putten et al., 1981; Priebe and Gruyters, 1994; Broker et al., 1995; Priebe et al., 2009). This study shows that a positive change in voluntary patients' treatment satisfaction over time can lead to improvement in other outcomes, such as perceived coercion. The positive change in satisfaction in this study occurred naturally, in the absence of any specific interventions. Thus, treatment interventions may aim to improve patient satisfaction and improved satisfaction may in turn lead to overall more positive outcomes, as suggested in previous research (Priebe et al., 2009).

In the absence of studies using independent assessments of admission and treatment processes, we do not know to what extent patients' experiences reflect factual interactions and to what extent their view of events was shared by others involved in the process. For example, when patients believe that their treatment preferences were not considered, clinicians might feel that patients' opinions were indeed considered, but were seen as inadequate solutions in the given crisis situation (Jones et al., 2008). Evidence indicates that psychiatrists do seek to implement a patient-centred practice and are concerned about the possible detrimental effects of coercion, but are willing to overrule patients' wishes when they judge this to be in their best interest (Seale et al., 2006). When such disagreements occur and clinicians' decisions are implemented, the experience of some coercion on the part of the patients might be unavoidable. However, our findings indicate that when patients feel that professionals genuinely care about them and offer them some degree of participation in treatment decisions, hospitalisation might be viewed in a less negative light and perceptions of coercion might be kept to a minimum (Bennett et al., 1993). Providing information, offering patients sufficient time to consider their options and involving them in care planning may also help achieve this (Katsakou and Priebe, 2007).

This study shows that a significant proportion of voluntary patients feel coerced into hospital admission and subsequent treatment and sheds light on experiences leading to perceived coercion. Taking patients' treatment preferences into account, making them feel respected and involving them in decisions, and increasing their satisfaction with hospital treatment are not only requirements of good medical practice; they might also help reduce their perceived coercion and improve other treatment outcomes. However, how to achieve this in everyday practice, particularly during a crisis situation and an acute hospital admission, is less clear. Future research may focus on developing and testing specific interventions in this area.

\section{Acknowledgement}

This study was supported by a grant from the European Commission (Quality of life and Management of Living Resources Programme, contract number QLG4-CT-200201036). We are grateful to all interviewed patients and staff of the participating hospitals. We also thank all the researchers involved in data collection.

\section{References}

American Psychiatric, Association, 1994. Diagnostic and Statistical Manual of Mental Disorders-Fourth Edition. American Psychiatric Association, New York.

Beck, J.C., Golowka, E.A., 1988. A study of enforced treatment in relation to Stone's "thank you" theory. Behavioral Sciences \& the Law 6, 559-566.

Bennett, N., Lidz, C.W., Monahan, J., Mulvey, E.P., Hoge, S.K., Roth, L.H., Gardner, W., 1993. Inclusion, motivation, and good faith: the morality of coercion in mental hospital admission. Behavioral Sciences \& the Law 11, 295-306.

Bennewith, O., Amos, T., Lewis, G., Katsakou, C., Wykes, T., Morriss, R., Priebe, S., 2010. Ethnicity and coercion among involuntarily detained psychiatric in-patients. The British Journal of Psychiatry 196, 75-76.

Bindman, J., Reid, Y., Szmukler, G., Tiller, J., Thornicroft, G., Leese, M., 2005. Perceived coercion at admission to psychiatric hospital and engagement with follow-up-a cohort study. Social Psychiatry and Psychiatric Epidemiology 40, 160-166. 
Boyatzis, R.E., 1998. Transforming Qualitative Information: Thematic Analysis and Code Development. Sage publications, New York.

Broker, M., Rohricht, F., Priebe, S., 1995. Initial assessment of hospital treatment by patients with paranoid schizophrenia: a predictor of outcome. Psychiatry Research $58,77-81$.

Gardner, W., Hoge, S., Bennett, N., Roth, L.H., Lidz, C.W., Monahan, J., Mulvey, E.P., 1993. Two scales for measuring patients' perceptions of coercion during mental hospital admission. Behavioral Sciences \& the Law 11, 307-321.

Gardner, W., Lidz, C.W., Hoge, S.K., Monahan, J., Eisenberg, M.M., Bennett, N.S., Mulvey, E.P., Roth, L.H., 1999. Patients' revisions of their beliefs about the need for hospitalization. The American Journal of Psychiatry 156, 1385-1391.

Gilburt, H., Rose, D., Slade, M., 2008. The importance of relationships in mental health care: a qualitative study of service users' experiences of psychiatric hospital admission in the UK. BMC Health Service Research 8, 92.

Hiday, V.A., Swartz, M.S., Swanson, J., Wagner, H.R., 1997. Patient perceptions of coercion in mental hospital admission. International Journal of Law and Psychiatry $20,227-241$.

Hoyer, G., Kjellin, L., Engberg, M., Kaltiala-Heino, R., Nilstun, T., Sigurjonsdottir, M., Syse, A., 2002. Paternalism and autonomy - a presentation of a Nordic study on the use of coercion in the mental health care system. International Journal of Law and Psychiatry 25, 93-108.

Jones, G., Jancovic Gavrilovic, J., McCabe, R., Becktas, C., Priebe, S., 2008. Treating suicidal patients in an acute psychiatric day hospital: a challenge to assumptions about risk and overnight care. Journal of Mental Health 17, 375-387.

Kallert, T.W., Glockner, M., Onchec, G., Raboch, J., Karastergiou, A., Solomon, Z. Magliano, L., Dembinskas, A., Kiejna, A., Nawka, P., Torres-González, F., Priebe, S., Kjellin, L., 2005. The EUNOMIA project on coercion in psychiatry: study design and preliminary data. World Psychiatry 4, 168-172.

Kallert, T.W., Priebe, S., McCabe, R., Kiejna, A., Rymaszewska, J., Nawka, P., Ocvár, L. Raboch, J., Stárková-Kalisová, L., Koch, R., Schützwohl, M., 2007. Are day hospitals effective for acutely ill psychiatric patients? A European multicentre randomised controlled trial. The Journal of Clinical Psychiatry 68, 278-287.

Kaltiala-Heino, R., Laippala, P., Salokangas, R.K., 1997. Impact of coercion on treatment outcome. International Journal of Law and Psychiatry 20, 311-322.

Katsakou, C., Bowers, L., Amos, T., Morriss, R., Rose, D., Wykes, T., Priebe, S., 2010. Coercion and treatment satisfaction among involuntary patients. Psychiatric Services 61, 286-292.

Katsakou, C., Priebe, S., 2006. Outcomes of involuntary hospital admission - a review. Acta Psychiatrica Scandinavica 114, 232-241.

Katsakou, C., Priebe, S., 2007. Patients' experiences of involuntary hospital admission and treatment: a review of qualitative studies. Epidemiologia e Psichiatria Sociale $16,172-178$.

Kjellin, L., Andersson, K., Bartholdson, E., Candefjord, I., Holmstrom, H., Jacobsson, L. Sandlund, M., Wallsten, T., Ostman, M., 2004. Coercion in psychiatric care: patients' and relatives' experiences from four Swedish psychiatric services. Nordic Journal of Psychiatry 58, 153-159.
Lidz, C.W., Hoge, S.K., Gardner, W., Bennett, N.S., Monahan, J., Mulvey, E.P., Roth, L.H., 1995. Perceived coercion in mental hospital admission. Pressures and process. Archives of General Psychiatry 52, 1034-1039.

Lidz, C.W., Mulvey, E.P., Hoge, S.K., et al., 1998. Factual sources of psychiatric patients' perceptions of coercion in the hospital admission process. The American Journal of Psychiatry 155, 1254-1260.

Luckstead, A., Coursey, R.D., 1995. Consumer perceptions of pressure and force in psychiatric treatments. Psychiatric Services 46, 146-152.

McKenna, B.G., Simpson, A., Coverdale, J.H., Laidlaw, T.M., 2001. An analysis of procedural justice during psychiatric hospital admission. International Journal of Law and Psychiatry 24, 573-581.

Miles, M.B., Huberman, A.M., 1994. Qualitative Data Analysis. Sage Publications, New York.

Monahan, J., Hoge, S.K., Lidz, C., Roth, L.H., Bennett, N., Gardner, W., Mulvey, E., 1995 Coercion and commitment: understanding involuntary mental hospital admission. International Journal of Law and Psychiatry 18, 249-263.

Priebe, S., Gruyters, T., 1994. Patients' and caregivers' initial assessments of day-hospital treatment and course of symptoms. Comprehensive Psychiatry 35, 234-238.

Priebe, S., Gruyters, T., Heinze, M., Hoffmann, C., Jäkel, A., 1995. Subjective criteria for evaluation of psychiatric care. Methods for assessment in research and routine care. Psychiatrische Praxis 22, 140-144.

Priebe, S., Jones, G., McCabe, R., Briscoe, J., Wright, D., Sleed, M., Beecham, J., 2006. Effectiveness and costs of acute day hospital treatment compared with conventional in-patient care. The British Journal of Psychiatry 188, 243-249.

Priebe, S., Katsakou, C., Amos, T., Leese, M., Morriss, R., Rose, D., Wykes, T., Yeeles, K. 2009. Patients' views and readmissions 1 year after involuntary hospitalisation. The British Journal of Psychiatry 194, 49-54.

Priebe, S., Katsakou, C., Gloeckner, M., Dembinskas, A., Fiorillo, A., Karastergiou, A. Kiejna, A., Kjellin, L., Nawka, P., Onchev, G., Raboch, J., Schuetzwohl, M., Solomon, Z., Torres-González, F., Wang, D., Kallert, T., 2010. Patients' views of involuntary hospital admission after one and three months: a prospective study in eleven European countries. The British Journal of Psychiatry 196, 179-185.

Rogers, A., 1993. Coercion and "voluntary" admission: An examination of psychiatric patient views. Behavioral Sciences \& the Law 11, 259-268.

Seale, C., Chaplin, R., Lelliott, P., Quirk, A., 2006. Sharing decisions in consultations involving anti-psychotic medication: a qualitative study of psychiatrists' experiences. Social Science \& Medicine 62, 2861-2873.

Sorgaard, K.W., 2007. Satisfaction and coercion among voluntary, persuaded/pressured and committed patients in acute psychiatric patients. Scandinavian Journal of Caring Sciences 21, 214-219.

Van Putten, T., May, P., Marder, S., Wittmann, L.A., 1981. Subjective response to antipsychotic drugs. Archives of General Psychiatry 38, 187-190.

Ventura, J., Green, M.F., Shaner, A., Liberman, R., 1993. Training and quality assurance with the Brief Psychiatric Rating Scale: “The Drift Busters". International Journal of Methods in Psychiatric Research 3, 221-224. 